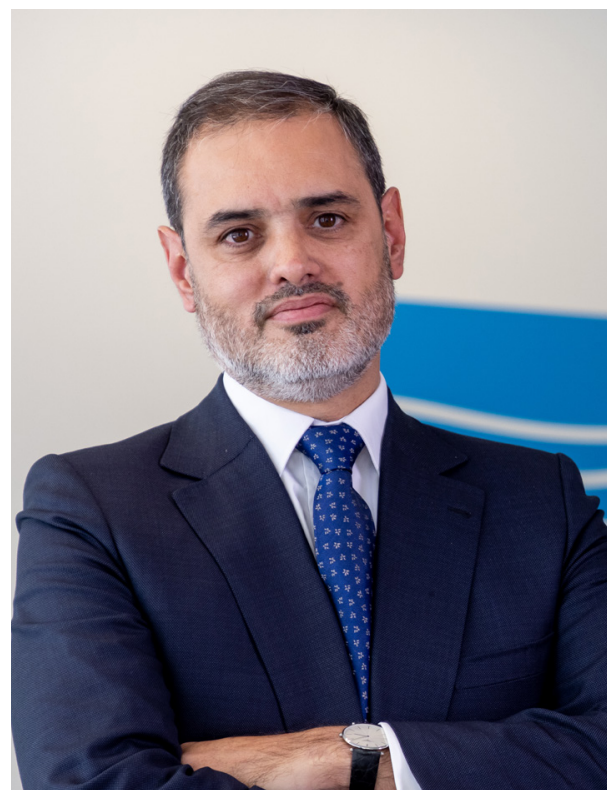

\title{
Colocar a Investigação ao Serviço dos Doentes
}

\section{Clinical Research for the Benefit of Patients}

Rui Diniz ${ }^{1}$

Das gerações mais jovens às mais velhas, é unânime dizer que estamos hoje a viver dos tempos mais desafiantes e exigentes da nossa história individual e coletiva.

No último ano, a pandemia de COVID-19 fez com que a saúde assumisse o lugar cimeiro das preocupações dos cidadãos e da nossa sociedade, ao mesmo tempo que desafiou a resiliência, a competência e a superação das instituições de saúde e dos seus profissionais.

E se, um pouco por todo o mundo, a pandemia provocou impactos, nunca antes vistos, na prestação de cuidados de saúde, é também inegável o impacto que trouxe às atividades de ensino, de formação, de investigação de outras doenças para além da COVID, atividades essenciais para os avanços e melhorias nos cuidados de saúde dos doentes.

Nunca como hoje se tornou tão evidente a importância da ligação entre a ciência e a prestação de cuidados de saúde e o poder desta união. Uma não deveria viver sem a outra, porque se queremos contribuir para o progresso da Medicina e da Ciência, é fundamental apostarmos numa investigação que se coloca verdadeiramente ao serviço da saúde das pessoas.

Na CUF, orgulhamo-nos de, desde a nossa origem, olharmos para o investimento na investigação clínica e na cooperação com as instituições universitárias como prioridades estratégicas, determinantes para assegurar o acesso às últimas inovações clínicas e uma prestação de cuidados de saúde cada vez mais diferenciadora. E mesmo em ano de pandemia, e em paralelo com o esforço da CUF no combate nacional contra a COVID-19, reforçámos a ligação à academia pois, enquanto prestadores de saúde de referência, reconhecemos a relevância do nosso contributo e em como este se traduz em melhorias concretas na saúde e na qualidade de vida dos doentes.

\section{LANÇAMENTO DO CENTRO DE SIMULAÇÃO CUF}

Com uma aposta clara na diferenciação clínica, 2020 fica marcado pelo lançamento do Centro de Simulação da CUF Academic Center, um projeto desenvolvido com o objetivo de reforçar a capacidade formativa em saúde da CUF e que conta com a NOVA Medical School como parceira. Projetado em linha com os gold standards nacionais e internacionais na área biomédica, o Centro de Simulação reforça o trabalho que tem sido feito na formação pré e pós-graduada e posiciona a CUF como uma referência na capacitação de profissionais de saúde.

Esta ligação às instituições universitárias constitui-se como um vetor essencial da atividade da CUF, que tem procurado aprofundar, ano após ano, diversas parcerias com instituições universitárias de referência nacional e internacional.

A este propósito destaco o Tagus TANK, o consórcio constituído com a Universidade NOVA de Lisboa, que concilia a prática hospitalar, com o ensino e a investigação e que, de forma inédita, abrange múltiplas disciplinas e faculdades como Direito, Economia, Engenharia e outras escolas da Universidade NOVA. 
São várias as iniciativas que temos promovido no âmbito desta parceria, sendo exemplo disso o programa de apoio aos Projetos de Investigação em Medicina que financia projetos que desenvolvam novas linhas de investigação médica de excelência, em áreas estratégicas como a Oncologia, Doenças Cardio-metabólicas, Neurociências, Ortopedia, Qualidade de Vida, Ética em Saúde, ou o apoio ao desenvolvimento de Programas de Doutoramento pelos profissionais de saúde da CUF junto da NOVA Medical School ou de outras unidades orgânicas da Universidade NOVA de Lisboa.

A colaboração da CUF com entidades de referência vai desde o ensino à investigação e em 2020, importa também salientar o protocolo desenvolvido com a Fundação Gulbenkian, numa parceria que inclui colaborações ao nível da investigação, doutoramentos e formação, tendo-se iniciado, desde já, alguns estudos conjuntos na área da COVID-19.

A Fundação Gulbenkian, através do Instituto Gulbenkian de Ciência, tem promovido a cultura e os valores científicos na sociedade e desenvolvido investigação de excelência, pelo que a sua associação à CUF é motivo de orgulho e traduz-se numa aproximação que trará com certeza uma partilha e dinamização de conhecimento que nos ajudará a promover melhores práticas de saúde.

\section{CRESCIMENTO DOS PROJETOS DE MÉDICOS-INVESTIGADORES EM ANO DE PANDEMIA}

Apesar da atual conjuntura representar um desafio sem precedentes, na área de investigação há a salientar, mesmo em ano de pandemia, o aumento significativo de projetos por iniciativa dos médicos-investigadores da CUF.

Do ponto de vista dos ensaios clínicos, que em 2011 se iniciaram na CUF e que desde aí têm vindo a ter um crescimento sustentado e progressivo, só em 2020 registaram-se 46. De salientar que a maioria são da área de Oncologia, área para a qual a CUF, o primeiro e maior prestador privado de saúde em Portugal a diagnosticar e tratar cancro desde há 36 anos, tem vindo a assumir um papel cada vez mais relevante, participando num crescente número de ensaios clínicos em Portugal.

Trata-se de uma participação a par com muitas instituições de reconhecimento internacional, o que é um sinal de grande responsabilidade para a CUF que assume assim o compromisso de ir além da prestação de cuidados de saúde de qualidade e contribuir igualmente para a descoberta e para o conhecimento científico que permitam oferecer mais esperança aos doentes oncológicos.

\section{A APOSTA NUMA INVESTIGAÇÃO AO SERVIÇO DA SAÚDE DOS PORTUGUESES}

Na CUF apresentamos um modelo de prestação de cuidados de saúde assente na procura contínua de soluções para dar resposta às necessidades dos doentes, de acordo com as melhores práticas, a excelência tecnológica e a mais recente e comprovada evolução científica.

Prosseguiremos, por isso, com a nossa missão de promover e apoiar iniciativas que cumpram estes objetivos. É o que fazemos há vários anos, através das Bolsas de Doutoramento em Medicina e Enfermagem ou com a Bolsa D. Manuel de Mello - em conjunto com a Fundação Amélia de Mello - premiando jovens médicos. Lançámos ainda, recentemente, o programa de Projetos de Investigação Clínica que visa impulsionar e apoiar as iniciativas de investigação que contribuam para um projeto clínico diferenciador nos hospitais e clínicas CUF.

Paralelamente, e enquanto parceiros fundadores da AHEAD - Advanced Health Education, a primeira escola de pós-graduação da Europa dedicada a todos os profissionais de saúde, que nasceu em 2019, fruto do reconhecimento da necessidade de atualização dos profissionais da área, continuaremos a promover o desenvolvimento e a inovação no conhecimento em saúde.

Áreas que promovemos também através da divulgação da atividade científica, designadamente aqui, na Gazeta Médica, uma revista científica que tem como missão promover o conhecimento de excelência em Medicina, privilegiando a publicação de artigos atuais, de utilidade na prática clínica, com rigor científico e metodológico. Publicação da CUF que viu reconhecida recentemente a sua relevância a nível nacional e internacional com a indexação no SciELO - Scientific Electronic Library Online, rede internacional que reúne atualmente publicações de 15 países, e cuja equipa está de parabéns, assim como todos os médicos-investigadores-cientistas que, ao longo dos anos, têm contribuído com a sua experiência, competência e conhecimento para enriquecer as páginas desta revista.

Termino salientando a vontade e intenção da CUF prosseguir com a sua aposta sustentada na promoção e desenvolvimento científicos, através da formação e capacitação dos seus profissionais e também na divulgação da sua atividade científica. Aposta que apresenta objetivos claros e que são o foco da nossa estratégia: contribuir para o progresso da Medicina e da Ciência em Portugal e para uma investigação que se coloca verdadeiramente ao serviço da saúde dos portugueses. 